\title{
UM COMPUTADOR POR ALUNO: UM DOS ÍCONES DA MODERNIZACC̃̃O DA ESCOLA BRASILEIRA NA SEGUNDA DÉCADA DO SÉCULO XXI
}

\author{
Luani de Liz Souza* \\ Universidade do Estado de Santa Catarina (UDESC) \\ Lisley Canola Treis Teixeira** \\ Universidade Federal de Santa Catarina (UFSC) \\ Celso João Carminati ${ }^{* *}$ \\ Universidade do Estado de Santa Catarina (UDESC)
}

RESUMO: O objeto central deste texto é a análise de parte das discussões sobre o Programa Um Computador por Aluno, denominado PROUCA, que faz parte das políticas públicas educacionais no Brasil. O artigo é um estudo específico da pesquisa realizada no Projeto Aulas Conectadas? "Mudanças curriculares e aprendizagem colaborativa entre as escolas do projeto UCA em Santa Catarina" (2012 a 2013). Os fundamentos teóricos que se tecem com a empiria se vinculam à noção de cultura material escolar, à cultura escolar e à modernidade. Entre a observação participante e o cruzamento com as fontes documentais, buscou-se compreender as relações entre a materialidade digital, o laptop - UCA, com alguns elementos da política educacional suscitados pelo propósito de inovação escolar a partir deste "novo" objeto de ensino na prática escolar do Colégio de Aplicação da Universidade Federal de Santa Catarina.

Palavras-chave: Educação. Materialidade digital na escola. PROUCA política educacional.

http://dx.doi.org/10.1590/0102-4698136515

"Doutoranda em Educação: Linha de Pesquisa História e Historiografia da Educação, Programa de PósGraduação em Educação da Universidade do Estado de Santa Catarina - UDESC. Grupo de Pesquisa Observatório de Práticas Escolares. Grupo de Pesquisa Objetos da Escola. E-mail: luani.liz.souza@gmail.com "* Doutoranda em Educação: Linha de Pesquisa Sociologia e História da Educação, Programa de PósGraduação em Educação da Universidade Federal de Santa Catarina - UFSC. Docente do Colégio de Aplicação da Universidade Federal de Santa Catarina. Grupo de Pesquisa Observatório de Práticas Escolares. E-mail: canolatt@uol.com.br

"** Doutor em Educação: Universidade Federal de Santa Catarina. Professor-Pesquisador do Departamento de Pedagogia e Programa de Pós-Graduação em Educação na Universidade do Estado de Santa Catarina UDESC. Grupo de Pesquisa Observatório de Práticas Escolares. E-mail: cjcarminati@gmail.com 


\title{
ONE COMPUTER PER STUDENT: ONE OF THE ICONS OF BRAZILIAN SCHOOL'S MODERNIZATION IN THE XXI CENTURY'S SECOND DECADE
}

\begin{abstract}
The central object of this paper is the analysis of part of the discussions on the project "One Computer Per Student", also known as PROUCA, which is part of the educational public policy in Brazil. The article is a research's specific study conducted in the Project Connected Classes? "Curricular changes and collaborative learning among schools in UCA Project in Santa Catarina", (2012 to 2013). The theoretical fundaments that weave with the analyzed empirically link the notions of school material culture, school culture and modernity. Among the participant observation and the junction with documentary sources, it was sought to understand the relationship between digital materiality (the laptop - UCA) and some elements of educational policy with the purpose of school innovation arising from this "new" teaching object in school practice at the Application School from the Federal University of Santa Catarina.
\end{abstract}

Keywords: Education. Digital materiality in school. PROUCA-Educational policy.

\section{INTRODUÇÃO}

"A lição da cultura material é que, quanto mais deixamos de notá-la, mais poderosa e determinante ela se mostra."

(Daniel Miller)

Historicamente, os objetos e a cultura material passaram a ser integrados aos métodos pedagógicos de inovação da escola desde a transposição da pedra de ardósia para o caderno, do lápis de pedra para o de grafite, da caneta tinteiro para a caneta esferográfica, do quadro para os projetores, da folha de papel à tela do computador e tantos outros exemplos, que imprimem uma relação explícita da produção industrial e comercial aos artefatos e métodos escolares.

Diante da expectativa de que uma instituição escolar deveria traduzir o mundo prático ${ }^{1}$ para seus alunos, com a intenção de promover uma socialização adequada para subsidiá-los na vida, os sentidos de uma materialidade escolar passam a ser determinantes nesse processo. Ao estarem inseridos na escola, e no cotidiano dos alunos, os computadores portáteis introduzidos pelo governo no Programa Um Computador por Aluno (PROUCA) em nível nacional espelham a realidade social e econômica, com suas tecnologias e desafios que impõem sobre os professores uma responsabilização maior quanto ao processo de formação. 
Isso consiste em dizer que não há um objeto na materialidade escolar dissociado das dimensões sociais, políticas e históricas. No processo histórico de constituição da escola, e na consequente inserção de objetos em seu cotidiano, corre o interesse de mercado sobre as políticas de educação que se encontram ainda sob o jugo da pressão social e econômica. Daí advém a presença de alguns objetos escolares que são por vezes aleatórios à estrutura escolar, mas que, no entanto, estão ali como símbolo de modernização da instituição.

Quando afirmamos isso, nos referimos a iniciativa de implementação do Programa Um Computador por aluno (PROUCA), que foi subdividido em duas fases, sendo uma de experimentação, na qual os computadores foram doados por três empresas privadas distintas e entregues a cinco escolas públicas diferentes, nas cidades de São Paulo - SP, Porto Alegre - RS, Palmas - TO, Piraí - RJ e Brasília - DF. Já na segunda fase, foram encaminhados 150 mil laptops para 300 escolas públicas e foi ofertada capacitação para os educadores por meio do e-ProInfo ${ }^{2}$ - que contou com um ambiente colaborativo de aprendizagem. Esse programa vem de outras realidades, de países onde o investimento em educação é alto e tanto pais quanto alunos pressionam a escola para o uso desses artefatos nos ambientes escolares.

Na década de 1990, as escolas brasileiras incorporaram à sua estrutura física os laboratórios de informática como uma forma de proporcionar aos alunos acesso às novas tecnologias. No entanto, uma contradição se instaurou: não havia, assim como ainda não há, computadores suficientes para todos os alunos e o tempo escolar nesses laboratórios era limitado. Estar em um espaço institucional com hora marcada e com restrições de tempo para seu uso não favorecia os alunos e divergia das metas de inseri-los nas práticas sociais em torno da tecnologia digital.

Segundo dados do Instituto Brasileiro de Geografia e Estatística (IBGE) referentes ao Censo Demográfico de 2010 o percentual da população das Grandes Regiões que não possuía computadores chegava à casa dos $61,7 \%$. Diante das expectativas sociais de integração das tecnologias no âmbito educacional e de que a mobilidade e a presença da materialidade produzissem um novo método pedagógico investiu-se nas últimas duas décadas do século XXI em diferentes projetos de informática na educação e na capacitação de professores, via experiências como o ProInfo ${ }^{3}$ e outros programas afins com as denominadas tecnologias educacionais.

Em 2010, a partir da Lei $n^{\circ} 12.249$, de 11 de junho, o Programa Um Computador por Aluno ${ }^{4}$ é implantado no Brasil. Essa lei é inspirada no projeto idealizado pelo pesquisador norte 
americano Nicholas Negroponte ${ }^{5}$, denominado Um laptop para cada criança. $\mathrm{Na}$ dimensão educacional o projeto ambicionava a inclusão digital, a melhoria da qualidade da educação e, atrelado a isso, o desenvolvimento da indústria tecnológica digital.

Nesse sentido, pretendemos analisar o percurso do Programa Um Computador por Aluno (PROUCA) ${ }^{6}$ a partir do contexto escolar. Dessa forma, tomando esse objeto como materialidade escolar no cenário do Colégio de Aplicação da Universidade Federal de Santa Catarina, no recorte desta pesquisa, nos anos iniciais do Ensino Fundamental, discutiremos a inserção do UCA, no período de 2010 a 2012 naquela instituição. Parte desse estudo está relacionado à experiência no projeto Aulas conectadas? Mudanças curriculares e aprendizagem colaborativa entre as escolas do projeto UCA em Santa Catarina $^{7}$ nos anos de 2012 e 2013, financiado pelo CNPQ a partir do Edital CNPq/CAPES/SEED-MEC n. 76/2010, e desenvolvido pelo grupo de pesquisas do Observatório de Práticas Escolares da Universidade do Estado de Santa Catarina (UDESC) ${ }^{8}$.

Nessa instituição, o grupo de pesquisa do Projeto Aulas Conectadas, em conjunto com seis professoras do $4^{\circ}$ e $5^{\circ}$ anos iniciais do Ensino Fundamental, realizou o estudo de modo colaborativo. Além das professoras, participaram da pesquisa 125 alunos que compunham as turmas. Atendendo às questões éticas na pesquisa, apresentaramse Termos de Consentimento de pesquisa, aprovados pelo Comitê de Ética da UDESC. A identidade dos participantes da pesquisa será preservada, pois cada indivíduo será identificado por um número, letra ou por um nome "fictício" (SANTA CATARINA, 2010).

As dinâmicas da pesquisa teceram-se entre as observações diretas e os participantes, a experiência vivencial e a coleta de dados. A pesquisa no Colégio Aplicação se definiu como um processo de pesquisa colaborativa, em que o grupo de pesquisa do projeto Aulas Conectadas? participava e integrava as atividades em conjunto com as professoras e, do mesmo modo, as professoras eram pesquisadoras. Nesse contexto, a pesquisa estende seus sentidos, de acordo com Ibiapina e Ferreira (2007, p. 31):

[...] dar conta não somente da compreensão da realidade macrossocial, mas, sobretudo, em dar poder aos professores para que eles possam compreender, analisar e produzir conhecimentos que mudem essa realidade, desvelando as ideologias existentes nas relações mantidas no contexto escolar.

Como a pesquisa envolvia uso de computadores, a observação participante permitiu uma reconfiguração tanto do pesquisador externo quanto das professoras-pesquisadoras, que passaram no 
conjunto da pesquisa a observar e a experienciar. A partir das práticas com o aparelho tecnológico UCA, foram realizadas anotações e relatos por professores e pesquisadores do Aulas Conectadas? Além dos relatórios e das discussões do grupo de pesquisadores/ professores, que apresentavam os processos de desenvolvimento das aulas, de aprendizagem, discussões sobre o currículo, eles também descreviam a interação do aluno com a tecnologia e os detalhes da presença dessa materialidade na prática do cotidiano escolar.

Uma pista importante nesse cenário, de abordagem micro de uma pesquisa mais ampla, é a viabilidade da interlocução entre o grupo externo de pesquisadores e o professor/pesquisador. Como afirma Severino (2007, p. 15) '[...] em uma dimensão social, o que confere o seu sentido político. [Na pesquisa há] exigência de uma significação política englobante, [...]". Dar credibilidade à experiência da atividade científica na prática escolar é ainda um desafio. Fazer da relação do ensino básico objeto de pesquisa e estudo é ponderar sobre a e na prática escolar. Não é somente as observações que podem aglutinar sentido à pesquisa na escola, mas é a junção da prática da pesquisa à prática escolar. Mediante a forma específica da pesquisa no Colégio de Aplicação, o ato da produção do conhecimento não é um renegar das práticas docentes, mas sim, uma indagação sobre o contexto cultural e social que cercam os sujeitos escolares, as materialidades das escolas e, consequentemente, as políticas educacionais que atuam sobre a forma pedagógica.

Perante a compreensão de que falar das práticas escolares se faz a partir das culturas escolares, pluralizadas, assim, por tecermos a análise a partir dos conceitos em Viñao Frago (2000), Faria Filho (2007) e Vidal (2009), de que não há uma única cultura, nem mesmo em uma própria instituição escolar, porque as práticas são modeladas pelos sujeitos da escola engendradas por práticas sociais, educacionais e políticas específicas de um contexto.

[...] esses modos de fazer e de pensar - mentalidades, atitudes, rituais, mitos, discursos, ações, amplamente compartilhados, assumidos, não postos em questão e interiorizados, servem a uns e a outros para desempenhar suas tarefas diárias, entender o mundo acadêmico-educativo e fazer frente tanto às mudanças ou reformas como às exigências de outros membros da instituição, de outros grupos e, em especial, dos reformadores, gestores e Inspetores. (VIÑAO FRAGO, 2000, p. 100).

Mediante a esse entendimento sobre culturas escolares, o enfoque deste estudo no projeto Aulas Conectadas?, a partir das práticas pedagógicas das professoras dos anos iniciais do Colégio de Aplicação, priorizou como categoria de análise a materialidade escolar e a política educacional PROUCA. A partir das observações e práticas das professoras 
buscou-se compreender como esse objeto escolar, com poder simbólico de inovação educacional, esteve presente na prática escolar.

\section{ALGUMAS LIC̣ÕES DA CULTURA MATERIAL}

A cultura material escolar é uma parte relevante dos estudos da historiografia da educação, pois traz a possibilidade de indagar "sobre como a modernidade educativa foi sendo reinventada, a partir do signo de progresso que associava desenvolvimento científico e educativo à ampliação material da escola" (VIDAL, 2009, p. 43). Poderíamos então afirmar que a modernização da escola é tangenciada pela materialidade? E nesse caso específico, será pela implantação do Programa Um Computador por Aluno que se fará um processo de modernização da escola?

Para entendermos a inscrição dessa materialidade no contexto educacional, é importante atentar para o que afirma Souza (2007) que estudar a materialidade da escola é, pois, relevante para se compreender que os objetos escolares não esgotam em si o sentido cultural que possuem. Um objeto não encerra em si mesmo o sentido, trata-se de diferentes dimensões assumidas em cada lugar que reportam a uma ou outra prática social, cultural e, no caso da escola, como afirma Faria Filho (2007, p. 194), uma "forma escolar", compondo culturas escolares.

Desde meados da década de 1980, do século XX, notamos uma expansão crescente do uso da internet no Brasil e uma certa, mas lenta, apropriação e utilização nas escolas. Entre nós, mais recentemente, a cultura do uso de diferentes aparelhos de tecnologia digital móvel que possibilitam acessar a internet em conexões sem fio tem se difundido. Assim, diante desses avanços tecnológicos nos perguntamos: é viável uma escola sem computador? A escola deveria disponibilizar um computador para cada aluno??

Em nome de uma naturalização, acredita-se que a tecnologia digita $1^{10}$ inclui a todos. Dessa forma, no âmbito da instituição escolar passa a ser eminente a presença dessa materialidade como condição de pertencimento ao contexto digital. Tal fato já prediz uma construção simbólica relacionada a esse objeto, o UCA.

Examinando com mais atenção as perguntas, identifica-se que em ambas existe um elemento comum, a palavra computador. Esse artefato de uso e de sentidos múltiplos, constituído nas práticas sociais, relacionado a outras duas palavras das perguntas, escola e aluno, reposicionam o objeto, localizando-o e atribuindo-lhe um valor específico. Como indica Meneses (1998, p. 91): 
Os atributos intrínsecos dos artefatos, é bom que se lembre, incluem apenas propriedades de natureza físico-química: forma geométrica, peso, cor, textura, dureza etc. etc. Nenhum atributo de sentido é imanente. O fetichismo consiste, precisamente, no deslocamento de sentidos das relações sociais - onde eles são efetivamente gerados - para os artefatos, criando-se a ilusão de sua autonomia e naturalidade. Por certo, tais atributos são historicamente selecionados e mobilizados pelas sociedades e grupos nas operações de produção, circulação e consumo de sentido. Por isso, seria vão buscar nos objetos o sentido dos objetos.

Desse modo, os objetos na escola estão engendrados nas práticas sociais e seu deslocamento para a condição de escolarização necessita de reflexões. No caso do UCA, o computador acaba se inscrevendo como parte do processo de escolarização e, portanto, circunscrito a ela.

Além disso, as formas como se constituem as práticas variam devido a diferentes fatores, como por exemplo, os tempos e os espaços de uso, as condições e o contexto social aos quais pertence a escola, a organização e a dinâmica escolar, as crianças e os jovens que são atendidos, as práticas e os modos sociais com que professores têm condições de se envolver com um ou outro artefato de tecnologia digital, bem como sua formação. O que significa compreender que os usos e as práticas em torno do artefato localizado na escola constituem-se de forma peculiar em cada contexto.

Fantin e Girardello (2009) fazem reflexões sobre o tratamento da inclusão digital como mera inserção do material de tecnologia digital na escola. Segundo as autoras, "quando programas de inclusão ditos inovadores só enfatizam o acesso aos equipamentos, estão entendendo a escola simplesmente como lugar físico e não como forma cultural.” (FANTIN; GIRARDELLO, 2009, p. 75).

Todavia, podemos notar que as inovações, a inclusão digital ou a modernização estão ou são intrinsicamente associadas à presença da materialidade. Por exemplo, no que tange ao PROUCA, isso fica evidenciado no artigo $7^{\circ}$ da Lei ${ }^{\circ} 12.249$ de 2010, que ressalta que o programa deve promover a inclusão digital, mas afirma que isso ocorrerá: "[...] mediante a aquisição e a utilização de soluções de informática, constituídas de equipamentos de informática, de programas de computador (software) neles instalados e de suporte e assistência técnica necessária ao seu funcionamento." (BRASIL, 2010).

Faria Filho (2007) esclarece que nas práticas aquilo que acompanha uma demanda política para a escola não se comporta de forma homogênea e concisa, porque também acompanha, neste processo de escolarização, os sentidos e significados que estão em jogo na sua apropriação, bem como a racionalização da escola 
marcada pelas margens e fins de uso que cada uma produz, no caso, com a tecnologia digital. Nenhum lugar, nenhum cotidiano é mimético para que a materialidade possa estar numa relação social do homem de forma unilinear. Cada espaço social e cultural produz outros sentidos para e com a materialidade. Há no objeto um "estado social" diante de determinados grupos sociais, não há uma única forma de operacionalizar a materialidade, seus mecanismos são configurados para um funcionamento, mas as práticas modelam outras configurações da e na própria materialidade.

\section{O UCA COMO ARTEFATO PRODUZIDO PARA A ESCOLA?}

$\mathrm{Na}$ escola a materialidade que existe não é aleatória ao desejo de um ou outro tipo de escolarização, apropriação e consumo. A parede espessa, a luminosidade, o quadro-negro e sua posição na sala, as carteiras, o caderno, os armários, o material didático e outras materialidades, além das citadas, constituem a "maquinaria" e a "mão de obra" que estão ali presentes porque foram planejadas e produzidas para que continuamente nos apropriemos do seu sentido dentro e fora da escola.

Esse é um sinal de que são coisas entrelaçadas que produzem as materialidades da sociedade e que estão circulando na escola. Notamos no modelo do UCA marcas da história da escolarização e dos destaques tecnológicos da sociedade, pois seu formato similar aos netbooks ${ }^{11}$ produzidos em condição para tornarem-se mais móveis que os notebooks, como também seu formato associado aos notebooks de brinquedo, asseguram certa aceitabilidade social. Esse formato do objeto está diretamente associado à infância e à tecnologia ${ }^{12}$, algo produzido para um grupo específico. A configuração das alças do UCA, por exemplo, seu peso leve e sua abertura fácil recriam certas características das antigas lancheiras escolares, o que remete à lembrança dos seus usos cotidianos nos pátios escolares.

A presença do UCA na escola não é uma aparição voluntária. Como Lawn (2013) salienta, produzir uma escola para certo modelo pedagógico necessita um aparato material capaz de dar a ela tal sustentação. $\mathrm{Na}$ verdade, o autor lembra também que

“[...] lápis, papel barato, impressão a cores e testes de inteligência são ferramentas de escolarização, e sem esses utensílios e os sistemas de uso em que estão inseridos, as grandiosas narrativas da educação seriam incapazes de funcionar." (LAWN, 2013, p. 224) 
Diferente de objetos como quadro, giz, carteira, mesa do professor, flanelógrafo, material dourado, entre outros, o computador é um objeto produzido de forma independente da necessidade escolar, ou seja, ele não nasce para a escola e por causa dela, o que o difere como objeto dessas outras materialidades criadas e elaboradas para a escola, de fins puramente escolares. O UCA é uma remodelação dos netbooks, e, mais ainda, parece enunciar uma produção sistemática da indústria tecnológica ${ }^{13}$ para configurações "baratas" de aparatos tecnológicos para a massa.

Lawn (2013) argumenta que parte da função da escola no século XIX e XX compreendia socializar os alunos a uma materialidade e a uma relação técnica com ela que nem sempre era acessível a todos. Por exemplo, pode-se rememorar o esforço escolar de ensinar a segurar o lápis e a traçá-lo para a escrita, como uma "alfabetização técnica" ". No entanto, distinto do lápis, diante do computador a alfabetização técnica já não assume a mesma dimensão na escola, porque não se trata de um uso puramente instrumental. O propósito da escola envolve uma relação de aprendizagem interativa e de participação social com uso criativo dessa tecnologia.

Vivemos um tempo no qual a escola é acionada diretamente para projetar e incorporar ao ensino objetos e sistemas que difundam na instituição o caráter de eficiência tecnológica e que assegurem uma relação direta com o mundo prático. Portanto, nas práticas pedagógicas, ainda que pesem as ações singulares para o que se possa nomear como alguma inovação em cada escola, pela equipe pedagógica ou por professores, o pressuposto de inovação não está detido exclusivamente no laptop educacional.

Isso fica evidente quando as decisões que as escolas precisam tomar sobre o currículo são influenciadas pelos saberes atrelados às avaliações em função do próprio sistema nacional de avaliação da Educação Básica ou de dispositivos que formatam a escolarização. Isto é, as forças que atuam nas práticas curriculares se configuram as mesmas com ou sem a materialidade de tecnologia digital.

Outros objetos escolares, como: os cadernos, os gabinetes de curiosidades, os livros didáticos, serviram para mobilizar diferentes modelos pedagógicos, porém, a integração do UCA não veio para alicerçar uma inovação quanto ao modelo pedagógico. O que se narra em torno do UCA parece tentar acionar uma inovação a partir dele de forma independente das discussões sobre infância, juventude, conteúdo, conhecimento e informação, entre outros aspectos. Não há como desenvolver uma operação técnica de inovação diante 
dessa materialidade, pois na apropriação e no cotidiano a técnica ${ }^{15}$ se esvai de sentido, trazendo algumas dissonâncias entre as proposições políticas, a materialidade e a apropriação.

No caso do computador como um objeto de caráter tecnológico digital inserido na escola, os embates nacionais em torno do tema pelo governo federal, por vezes, são noticiados em formas como a que segue:

[...] desde 2007, até o final deste ano [2010] cerca de R 1 bilhão será gasto com programas de informatização das escolas. Incluindo aí a instalação de laboratórios, a capacitação de professores e também o programa Um Computador por Aluno [...]. Problema atual é a formação do professor. A expansão dos programas de inclusão digital nas escolas públicas brasileiras é inegável. Mas os computadores que chegam às salas de aula são muitas vezes subutilizados porque falta preparo dos professores para ensinar os alunos a utilizarem as máquinas para o aprendizado pedagógico. O senador Cristovam Buarque (PDT - DF), que foi ministro da Educação, não concorda que o único problema seja a falta de capacitação dos professores. Segundo ele, ainda está longe o dia que haverá um computador por aluno, como deseja a Presidência da República. Pelo menos 20 mil escolas não têm luz elétrica, como vão ter computador? (ABADE, 2010). ${ }^{16}$

De um lado, o Estado parece querer resolver a questão da inclusão digital com a escolarização da materialidade tecnológica digital e a responsabilidade pelo sucesso dos programas que são introduzidos nas escolas fica a cargo dos professores. Do outro lado, há um conjunto de indicativos que atestam que as condições reais para que isso se efetive não estão dadas. As questões de inclusão ou exclusão digital ficam reduzidas à presença do objeto, o computador, e a formação de professores.

Parece haver uma estratégia compensatória que reduz a inclusão digital à condição da presença da materialidade, pois nos critérios de participação do PROUCA já se enuncia certo afunilamento de seletividade na direção de grandes instituições (número de alunos maior que 500) e condições, como: as escolas deveriam ter obrigatoriamente energia elétrica e armários para os equipamentos; a localização da escola deveria ser próxima a Núcleos de Tecnologias Educacionais (NTE), a Instituições de Ensino Superior ou a Escolas Técnicas Federais, uma escola na capital do estado e outra na zona rural ${ }^{17}$.

Há uma reconversão do sentido inovação e modernização vinculada à materialidade e, principalmente, a inclusão digital parece ser pseudoinclusão ${ }^{18}$. Como aponta Carvalho (2012, p. 28) "a modernização propicia a emergência de duas tendências contraditórias num mesmo processo: integração e marginalização ${ }^{19}$." Assim, a modernização na escola atrelada à materialidade do $\mathrm{UCA}^{20}$ 
expressa a tendência da racionalização e orienta a ação social como padrão de produto, nesse caso objetivado no laptop educacional.

Há que se considerar que alguns alunos e seus familiares somente tiveram acesso a um equipamento tecnológico por meio do PROUCA. No entanto, diante das limitações de configuração do computador, seu uso foi limitado e aquém ao que se poderia considerar como inerente a uma dita eficiência tecnológica.

Uma proposta de força social pelo caráter de inclusão digital, que emerge nas proposições da Fundação OLPC que integrou a criação do PROUCA, sob os argumentos de mercado, "o barato com qualidade" merece algumas reflexões. A primeira está no fato de que se abre um novo nicho no mercado escolar público e fora dele, o mercado escolar privado, e do comércio varejista como forma de consumo. E a segunda, a partir das configurações dos laptops educacionais, que com a proposição do barato propõe um modelo de laptop para o mercado escolar que não apresenta as mesmas estruturas técnicas daquele do mercado varejista.

Isso fica evidente ao analisarmos o equipamento entregue de acordo com o Pregão n ${ }^{\circ}$ 107/2008, vencido pelo Consórcio CCE/ Digibras/Metasys, onde a empresa Metasys apresenta o seu produto intitulando-o de Solução Metasys para Educação - baseado nos Intel ${ }^{\circledR}$ Classmate PC. Se analisarmos o equipamento anunciado como base de referência para as estruturas do UCA, teríamos um equipamento de excelente eficiência técnica cuja apropriação poderia ocorrer de forma distinta nas escolas.

As implicações do objeto escolar em questão (UCA) na apropriação dos saberes escolares vêm amarradas a um ideal de reestruturação e modificação da prática pedagógica dirigida, mais efetivamente, ao corpo docente. Historicamente essa prática se apresenta ligada à proposição de inovação e mudanças, decididas e regimentadas externamente e verticalmente aos que "executam". Esse objeto escolar com todo o enunciado de impacto social, efetivamente percebido e detectado por meio da legislação que o insere no contexto educacional, não é introduzido no cotidiano escolar como um suporte que encerra em si mesmo um único propósito. Já é sabido que sua incursão no espaço escolar pode ser, e por vezes o é, a instalação de uma reverberação dos enunciados políticos a respeito da inclusão digital.

Parece que nesse debate a questão da integração do objeto escolar UCA em uma proposta de inovação curricular, ou de avanços tecno-sociais da educação, apresenta certa mentalidade e desígnio em que a reestruturação só decorre da capacidade das práticas pedagógicas dos docentes. 
Nesse sentido, os computadores compõem mais um eixo possível de abordagem na materialidade da escola, pois a incursão das novas tecnologias na sociedade faz com que a presença de computadores nas escolas provoque um debate acirrado sobre sua validade. Isso corresponde a dizer que "as práticas culturais e os sentidos partilhados atravessam os muros das escolas e se patenteiam no dia a dia das escolas brasileiras rurais e urbanas." (FARIA FILHO, 2007, p. 199). A modernização escolar parece ter que acompanhar a modernização da sociedade. Nesse sentido há uma valorização simbólica acoplada ao UCA.

\section{OLHARES E ALGUMAS EXPERIÊNCIAS: O UCA NOS ANOS INICIAIS DO COLÉGIO DE APLICAÇÃO NA UFSC}

Segundo dados do governo federal a implantação do PROUCA no Colégio de Aplicação da UFSC ocorreu em agosto de $2010^{21}$ e deveria contemplar 930 alunos e 100 professores. Porém, de acordo com o Informativo Aplicação de abril de $2011^{22}$, da instituição, "após 7 meses de espera, os 947 laptops educacionais destinados ao projeto UCA - Um Computador por Aluno - começaram a ser entregues [...]" (SANTA CATARINA, 2011, p. 1). Ainda sobre as informações de implantação, afirma-se que os computadores foram entregues em outubro de 2010, mas em virtude de uma incompatibilidade do sistema operacional e da rede na escola os laptops educacionais não foram repassados aos alunos. Com problemas de ordem técnica na banda larga, como também com o software do sistema operacional Metasys ${ }^{23}$ no produto $\mathrm{CCE}^{24}$, os quais geravam um erro que travava os equipamentos, foi preciso recolhê-los para sanar o problema. Isso levou os alunos a ter dúvida quanto à eficiência do laptop fornecido pelo PROUCA.

Mesmo aqueles alunos do Colégio de Aplicação, crianças e jovens, e seus responsáveis, que já tinham um significativo acesso à tecnologia digital, demonstraram inicialmente muita expectativa com a entrega do laptop UCA.

Aliado a isso, em breve levantamento nas turmas do $4^{\circ}$ e $5^{\circ}$ anos do Ensino Fundamental, que participaram do Projeto Aulas Conectadas da UDESC, a tecnologia digital na forma de laptops e computadores já era matéria inserida na vida da maioria dos alunos. Identificou-se em sala de aula uma média de duas a três crianças por turma que não tinham tido algum tipo de acesso, seja pela falta do equipamento ou por não ter acesso à internet. Além disso, decorrido algum tempo, aconteceram casos, poucos, de pais que quiseram 
devolver o laptop, alegando que não havia necessidade dele em casa já que a criança tinha seu próprio computador.

Pode-se dizer que o momento da entrega dos equipamentos vem acompanhado, como afirma Pesez (2005, p. 249) da "dimensão histórica, cronológica, da cultura material [que] soma-se, pois, a dimensão social e uma dimensão espacial", conclui-se que somente a presença do objeto no espaço escolar constituiu as problemáticas ${ }^{25}$ em seu uso e apropriação pedagógica e cultural. O que mais gera estranheza é que entre a Fase I Experimental (2007) e Fase II Piloto (2010) não se suscita os contextos e diversidades do espaço escolar. Assim, perguntamos: as dimensões espaciais das outras escolas escolhidas para os testes eram diferentes? $\mathrm{O}$ tipo de equipamento que foi encaminhado para o projeto piloto era diferente daquele recebido agora pela escola? Se o UCA é um objeto para a escolaridade por que as dimensões e configurações escolares geram problemas no momento da implantação?

Tais questões são suscitadas a partir do uso do UCA no Colégio de Aplicação onde alguns professores tiveram dificuldades técnicas com o equipamento ao desenvolverem atividades com os alunos, devido ao tamanho da tela, como por exemplo, nos jogos de memórias com cartas, pois esta não mostrava todas as cartas do jogo ao mesmo tempo e a barra de rolagem não garantia a percepção da posição das cartas que já haviam sido viradas.

Outro empecilho para o uso do UCA foi a falta de configuração do computador dos professores para realizar projeção conectado a um projetor, pois obrigava-os a um deslocamento constante até a carteira de cada aluno simultaneamente ou a vinda de vários deles até a mesa do professor para pedir orientações de como realizar o trabalho proposto.

Os trabalhos em PowerPoint com fotografias, vídeos ou músicas ocupavam muito espaço na memória, levando ao não funcionamento do equipamento que travava constantemente. Para evitar tais circunstâncias, em algumas atividades os professores começaram a recorrer ao uso do $\mathrm{PDF}^{26}$ para realizar a apresentação.

Quando os laptops começaram a apresentar defeitos houve um impasse quanto à manutenção dos mesmos. Por não serem comercializados, os mesmos deveriam receber suporte técnico dos seus fabricantes com possíveis ônus do conserto pagos pelo governo, mas que não foram atendidos nem por um nem por outro. Desse episódio, ficou a impressão que não se tratava de uma política pública que tivesse continuidade, pois, sem a manutenção dos computadores do projeto UCA, fica configurado um abandono do programa, fato que causou estranheza e transtorno na escola. 
As baterias dos laptops não mantinham sua carga por muito tempo. Consequentemente era preciso usar o computador ligado diretamente na corrente/tomada elétrica, dificultando a mobilidade do aluno. Como as salas de aula não foram projetadas com muitas tomadas, acabava por dificultar ainda mais essa situação da recarga das baterias. Somado a esses aspectos, os professores percebiam que faltavam condições para se apropriarem plenamente do uso e das possibilidades tecnológicas para estruturar o trabalho potencializando a tecnologia digital, bem como tempo para investigar e pesquisar programas, softwares mais leves que não acarretassem o travamento do UCA.

Entre a produção da necessidade de consumo e aquilo que se propõe como política de inclusão digital, nota-se que as situações evidenciadas nos usos do UCA decorrem especificamente das configurações dos equipamentos recebidos pela escola, que atendiam aos "requisitos mínimos" que estavam em conformidade com o Pregão no 107/2008 ${ }^{27}$. Porém, na leitura da Resolução/FNDE/CD $\mathrm{n}^{\mathrm{o}} 17$ de 10 de junho de 2010, pode-se identificar como os problemas surgidos na prática pedagógica também decorrem das alterações nas configurações dos computadores recebidos na escola.

Nessa resolução, o banco de memória de inicialização deveria ser expansível até $2 \mathrm{~GB}^{28}$, mas há uma mudança da configuração para 1 GB de memória RAM ${ }^{29}$. Além disso, os equipamentos recebidos possuíam uma memória de $3 \mathrm{~GB}$, apesar da exigência de a capacidade de armazenamento ser de $4 \mathrm{~GB}$, o mínimo requerido para a funcionalidade. Com isso a memória de 3 GB ficava ocupada praticamente com os softwares de instalação e com o sistema operacional.

Nessa mesma resolução são modificadas as especificações da tela, que no Pregão no 107/2008 era na dimensão de 7 polegadas passando para 8,9 polegadas. Com essa alteração da tela, fica claro que a proposição do equipamento do Pregão no 107/2008 quanto às questões visuais era problemática. A própria instituição OLPC também modificou as configurações da tela e já tinha proposto uma inovação para o toque sensível e para a alteração da capacidade de armazenamento para 8 GB. Tudo isso parece mera quantificação e comparação, todavia, refletir sobre o que cerca essa materialidade na escola envolve pensar no momento da entrega, nos espaços de mais uso dentro de uma escola, nas práticas não planejadas e prescritas, entre outros. As fronteiras entre os sistemas de uso e materialidade dentro e fora da escola apresentam questões de outra ordem e entram em debate na própria alfabetização digital. 


\section{ALÉM DA TÉCNICA - AS PRÁTICAS CULTURAIS}

Se no passado, nas primeiras experiências da escola pública como conhecemos hoje, eram necessárias horas de dedicação entre o caderno e o lápis, como pegar e apontar o lápis, como deixar a letra no espaço correto das linhas, se era necessário um outro caderno (de caligrafia) para tecnicamente orientar a intensão de escrita do aluno, em 2011, assim que as crianças ${ }^{31}$ do Ensino Fundamental do quarto e quinto anos receberam os computadores, elas experimentaram diversas funções no equipamento, entre elas, tirar fotos de si mesmas e de amigos da sala usando recursos de imagem que existiam para alterá-las. Os aspectos instrumentais (ligar, desligar, salvar, distinguir documento de texto, fazer download de programas básicos, entre outros) já faziam parte do repertório de quase todos os alunos das turmas. Diante disso, cabe refletir sobre o peso que se dá aos aspectos pedagógicos como se fossem alheios aos de ordem técnica. O momento de recepção e o desenvolvimento da alfabetização técnica ${ }^{31}$ ou mesmo do uso instrumental não se faziam necessários, pois as crianças apresentavam uma significativa familiaridade com o computador.

A presença desse projeto na escola muitas vezes suscitava discussões nos espaços fora da sala de aula, como nos intervalos, por parte dos professores e equipe pedagógica, pois as crianças deixavam de brincar (os conhecidos jogos interativos de correr e pular) para juntas se divertirem com jogos e trocar informações sobre interesses próprios utilizando os computadores do projeto.

Outro aspecto observado foi que as imagens que eram recolhidas pelas crianças no UCA retratavam o espaço da casa, da rua, das pessoas e animais que compõe as relações de sua vida fora do universo escolar. Essas imagens apareciam como papel de parede ou mesmo como arquivo. Contudo, algumas pastas com tais fotografias tiveram limitações, pois a capacidade de armazenamento do UCA era insuficiente, não atendia as expectativas e causava problemas como o travamento constante do computador. Para solucionar essas situações era necessário limpar as informações e imagens de uso pessoal das crianças para que fosse possível colocar arquivos de uso pedagógico. Assim, parece haver, inicialmente, um embate entre os usos pedagógicos e os usos no cotidiano.

A configuração do equipamento com pouco espaço de armazenamento reduz a possibilidade de socialização das imagens cotidianas, as quais são descartadas diante da necessidade pedagógica. Ou seja, em outra configuração, seria viável trocar/cambiar as práticas 
usuais das crianças com o equipamento e incluí-las no pedagógico, pois não criaria uma seletividade hierárquica do que é de fato um aprendizado diante dessa materialidade.

Não se trata somente de esvaziar a memória e introduzir os arquivos pedagógicos, isso delimita as possíveis (re)configurações de uso pela criança e suas marcas singulares no objeto. Aliás, os usos não pedagógicos e as marcas criadas no material eram um dos aspectos mais encantadores do uso do UCA, pois, como ele tinha uma aparência uniforme para todos os laptops, os alunos começaram a aplicar adesivos, a deixar registros pessoais com canetas, a montar seu papel de parede e a gerenciar as cores e formas de apresentação de seu computador móvel.

Inicialmente reconhece-se que a forma como esse objeto escolar foi socializado entre as crianças do Ensino Fundamental, e integrou a relação deles com o ambiente, demonstrou o valor simbólico dessa materialidade na escola. Esse aspecto ficava evidente porque as crianças trocavam experiências sobre o universo no qual transitavam no ciberespaço.

Como a escola considerou que o UCA deveria ser levado para casa, este se constituiu também um objeto de inclusão digital fora da escola, porque, para as crianças que não tinham seu próprio computador, ou que tinham um, mas que pertencia aos seus responsáveis, haveria mais liberdade de uso com o UCA.

Conclui-se que, de certa forma, em casa se produz outras experiências e nelas se pode, em alguns casos, promover um acesso ao ciberespaço para a família. Contudo, é preciso reconhecer que para aqueles que não tinham um computador em casa, a presença do UCA não representou necessariamente acesso a internet. Talvez alguns poucos tenham usufruído do ciberespaço em locais públicos onde se tem acesso gratuito à rede.

Um último aspecto que chamou a atenção nos usos culturais do objeto aparece na diferença com que os adultos da escola (professores, equipe pedagógica, técnicos e outros) pensavam sobre a postura corporal dos alunos ao usarem o computador. As referências que se tinha como adulto era de que para manipular os primeiros computadores, o aluno deveria ficar mais estático, numa postura mais formal, sentado, o computador sobre a mesa, como uma máquina pesada e barulhenta.

Um aspecto positivo desse projeto foi que na utilização do laptop UCA o formato fez com que as crianças se movessem pela escola de forma dinâmica com acesso à internet em diferentes lugares e esconderijos da instituição. Constata-se, contudo, que diante 
do relatado essas não são as práticas mais esperadas, pois elas são práticas culturais e não escolares. Nas relações de uso escolar estão em jogo alguns aspectos que abrangem os procedimentos didáticos, o rendimento escolar e os domínios do conteúdo de alcance do professor e dos alunos.

No caso do UCA, diante dos elementos presentes na proposta de avaliação dessa política educacional, as formas ditas do programa apontam para a adequação das práticas pedagógicas nos moldes propostos. No entanto, é fundamental salientar que essa modificação das práticas necessariamente dialoga com a tradição seletiva de conteúdos presentes na escola, construída pelas forças de legitimação do saber escolar tido como válido. O que, segundo Faria Filho (2007), explicita as culturas escolares que se constroem nos espaços e tempos da escola.

Os códigos de comunicação implícitos nos modelos de educação que agregam os objetos escolares-tecnológicos como o UCA, em um modelo uniforme e em que os mecanismos de socialização estão restritos a uma mera presença do objeto nos aspectos do desenvolvimento do currículo, apontam para uma contradição entre as perspectivas das reformas educacionais que anunciam remodelações, inclusão digital, e o sentido da prática e seus usos ao integrar esse novo objeto escolar.

A presença desse novo objeto no cotidiano da escola nos "moldes usuais", isto é, um objeto que enuncia a perspectiva de inclusão digital, mas que foi desenvolvido nos modelos convencionais da didática e do conhecimento, por vezes pode tão somente reproduzir as mesmas práticas pedagógicas e, assim, não assegurar a igualdade de oportunidades de avanço educacional como proposto inicialmente no projeto de Um Computador por Aluno. Até porque o avanço provavelmente se dá em outros espaços de práticas sociais distintas das educacionais, sendo que se usa o termo "provavelmente" nesta abordagem porque os outros conhecimentos são invisíveis ou não se constituem como significativos diante dos processos de avaliação educacional.

Apesar de a maioria dos conteúdos da internet estar próxima daqueles contidos e praticados nos currículos, o alcance desse meio de comunicação cria uma lacuna na certeza e na sua presença quando ele surge de forma diferenciada em sala, pois passamos a ter os mesmos conteúdos e ressignificações multifacetados.

A premissa de assegurar o objeto no espaço escolar como referência de transformação, ou inovação, lança sobre os professores problemas que são eminentemente sociais e políticos, haja vista que 
se trata de um equipamento que tem certas restrições de memória e armazenamento, ou mesmo cuja durabilidade e renovação/conserto são dimensionados pelo quanto se usa e que estão inatingíveis até o momento. Não se trata somente da condição de uso da tecnologia pelo professor, mas de reconhecer dois aspectos: primeiro que a formação do professor o instrumentalizou muito mais para uma alfabetização técnica do que digital; segundo porque o mundo prático tecnológico que circunda as crianças é, em algumas circunstâncias, anterior ou simultâneo ao seu ingresso escolar, seja como prática ou como desejo de ter algum objeto desse tipo.

O que prevalece ao se enunciar a situação da inclusão digital na educação, tende a recair muito fortemente na ideia da falta de domínio, por parte dos professores, do mundo tecnológico. Todavia, na proposta do UCA, dos professores exige-se dois domínios, o dos saberes usuais do ensino escolar com a tecnologia digital e a necessidade de saber driblar as falhas dos hardwares.

O professor passa diante dessa materialidade a fazer restrições e ou adaptações quanto ao seu uso, pois não se trata de um equipamento capaz de gerir os sentidos de produções que os sujeitos fazem no uso de computadores. Como há o confronto entre o uso cultural e o pedagógico, pelas próprias configurações do equipamento, pode-se identificar que essa materialidade não traduz as necessidades do trabalho pedagógico e de inclusão digital nas formas divulgadas quando da sua implantação. Parcialmente atinge o objetivo proposto em legislação uma vez que sugere inclusão pela materialidade sem contemplar as questões de condições de trabalho na sala de aula e o desafio das práticas culturais.

\section{CONSIDERACְÕES FINAIS}

As políticas para o desenvolvimento das tecnologias educacionais representam, hoje, parte da força motriz, acerca da materialidade como status de modernização da Educação Básica brasileira. Os artefatos escolares são anunciados nas políticas, como formas de inovar o processo pedagógico, porém parte da inovação que deve ocorrer na transformação/mudança na dinâmica do trabalho do professor esbarra nas condições paliativas das políticas, que muitas vezes, ficam a mercê do jogo econômico e social na inserção de novos aparelhos escolares no contexto da educação.

Os objetos escolares dispostos sob esse prisma, e também como articulação de transações comerciais, não asseguram práticas 
de modernização e inovação da escola e, além disso, apresentam certas dissonâncias quanto à intenção de inclusão que as políticas educacionais tendem a imprimir em suas proposições.

No caso deste estudo, o projeto UCA trazia consigo definições de inclusão digital e de transações comerciais, enfatizava a necessidade de ampliação e fomento das indústrias tecnológicas no Brasil, configurando-se no cenário escolar em estado de pseudomodernização, pois a sua presença na escola estava ligada a uma resposta política de internacionalização das tecnologias e à condição de ter o objeto como recurso ao moderno nas instituições escolares. Isto posto, a organização das transações comerciais a respeito do que é "escolar" e o que deve ou pode ser apropriado pela escola passa a ter importância para os governos, como também imprime certa notoriedade às escolas que adotam os novos modelos e objetos. A inserção do UCA na escola é tecida pelos valores e significados que um computador móvel tem na sociedade na dimensão de direito à inclusão digital, que coloca o aluno em processo constante de socialização. Ao mesmo tempo, está em jogo o caráter de mercadoria do objeto e estão em destaque os valores e os significados comerciais competitivos e produtivos da indústria.

Nesse jogo de interesses, valores e propósitos, constatamos que o UCA na prática educacional, por problemas de configurações do equipamento, não potencializava os desejos das crianças, bem como não contemplava o pleito da modificação dos processos pedagógicos. Em que pese a circulação de outros equipamentos na sociedade, seja como for, nem sempre os programas e pacotes do UCA estão relacionados à dinâmica do percurso com o conteúdo que está sendo desenvolvido, sendo necessária a busca por outros softwares e outros downloads que, infelizmente, por vezes, não são suportados pela configuração da máquina. Tal dificuldade a respeito das configurações dos equipamentos UCA prejudicava e, por vezes, inviabilizava o desenvolvimento das práticas pedagógicas que estavam no planejamento.

Esse objeto, propagado enquanto ícone modernizador da escola, cujo sentido social se articulou na perspectiva da inclusão digital, enquanto propulsor de um novo modelo pedagógico, se tornou mais um dos inúmeros projetos supostamente modernos e que tende a ser abandonado, como bem afirmou Lawn (2013) sobre "as modernidades abandonadas". Estamos diante de uma materialidade que em sua proposição econômica de baixo custo, nos interesses e transações entre as indústrias tecnológicas e o seu comprador, anulam o cuidado quanto às discussões pedagógicas 
acerca da necessidade de equipamentos potencialmente configurados e capazes de contribuir com os saberes escolares.

Fica evidente a partir do acompanhamento e dos usos dessa tecnologia na escola que as expectativas indicadas nas resoluções e nos documentos oficiais, quanto ao papel dessa materialidade, não são alcançadas, pois se constatou que a maior parte das baterias já não funcionava mais sem estar ligada às tomadas, que inúmeras teclas se desprenderam do teclado, que várias unidades do UCA foram dispensadas no setor de informática e na coordenação pedagógica, pois estes não funcionam mais ou não tem suporte técnico para troca ou conserto por parte do próprio projeto. Enfim, toda essa materialidade em processo de descarte e/ou abandonada é o indicativo de uma política governamental que poderíamos denominar de "paliativa". Pensar sobre toda a mobilização econômica e social advinda dessa ação e de seu "abandono" a posteriori evidencia como as políticas educacionais que tangenciam as questões tecnológicas são um efeito do prisma de modernização e de interesses econômicos, reafirmando um posicionamento do Estado como grande comprador de tecnologias, mas que fortalece a indústria de materiais/tecnologias escolares a partir do momento que se ausenta das eminentes necessidades de conservação e recuperação da materialidade.

As consequências são imediatas e também o prejuízo para a sociedade em termos de recursos públicos investidos. Dada a relação moderno/tecnologias, cada vez mais o fluxo do mercado conduz para a aquisição de determinadas tecnologias, que, logo, entram em desuso por tornarem-se obsoletas, bem como pela ausência do Estado quanto à habilitação e manutenção da materialidade, nas políticas educacionais ditas de continuas.

Ao mesmo tempo, no que tange à materialidade digital, o conceito de continuidade nas políticas parece se tornar uma questão ambígua, pois a resistência, o conserto ou conservação de um objeto dessa ordem tanto demonstra uma continuidade da política quanto o uso de um objeto obsoleto do ponto de vista tecnológico nas escolas, já que nessa área as inovações se multiplicam em curto prazo. Tal ambivalência cria um impasse nas decisões políticas que mesmo com recursos possam ainda se caracterizar como paliativas e descontínuas. O que não significa uma desculpa às situações de abandono de projetos com recursos públicos, mas um cuidado redobrado em tais decisões como agora o discurso da inovação via tablet em vez do laptop.

No contexto de inovação ou modernização pedagógica/ educacional está em jogo a questão econômica e de interesses de 
mercado, estabelecido entre a educação e a indústria tecnológica. Produz-se um tipo de processo de inclusão digital que denominamos pseudoinclusão, pois o fluxo ininterrupto das tecnologias e a ausência de continuidades nas políticas educacionais acionadas pela materialidade tecnológica põem em prática, mas não referenda, uma formação social do sujeito nos usos da tecnologia.

\section{REFERÊNCIAS}

ABADE, Luciana. MEC: Programas de inclusão digital estão entre os maiores do mundo. Jornal do Brasil. Brasília, abr. 2010. Disponível em: < http://www.jb.com.br/pais/ noticias/2010/04/03/mec-programas-de-inclusao-digital-estao-entre-os-maiores-domundo $>$. Acesso em: 12 jul. 2013.

BORGES, Martha Kaschny; SANTOS, Maximiliana Batista Ferraz dos. Um retrospecto histórico do Projeto OLPC no Brasil e no Mundo. Itajaí: VII Anped Sul, 2008.

BRASIL. Lei no. 12.249, de 11 de junho de 2010. Dispõe sobre a criação do Programa Um Computador por Aluno. Disponível em: < http://www.planalto.gov.br/ccivil_03/_ato20072010/2010/lei/112249.htm> Acesso em: 13 jan. 2013.

BRASIL. Programa Um Computador por Aluno, 2010. Dispõe sobre a implantação do PROUCA no Brasil. Disponível em: <http://www.uca.gov.br>. Acesso em: 16 jun. 2013.

BRASIL. Resolução FNDE/CD No 17, de 10 de junho de 2010. Dispõe sobre estabelecer normas e diretrizes para que os Municípios, Estados e o Distrito Federal se habilitem ao Programa Um Computador por Aluno - PROUCA, nos exercícios de 2010 a 2011, visando à aquisição de computadores portáteis novos, com conteúdos pedagógicos, no âmbito das redes públicas da educação básica. Disponível em: <https://www.fnde.gov.br/fndelegis/action/ UrlPublicasAction.php?acao $=$ abrirAtoPublico\&sgl_tipo $=$ RES\&num_ato $=00000017 \&$ seq ato $=000 \& v l r \_a n o=2010 \& s g l \_o r g a o=C D / F N D E / M E C>$ Acesso em: 13 jan. 2013.

BRASIL. Tribunal de Contas. Representação acerca de possiveis irregularidades na condução da fase de aceitação de proposta no Pregão Eletrônico n 107/2008, de 17 de dezembro de 2008. Dispõe sobre seleção e contratação de empresa especializada ou consórcio de empresas para a aquisição de 150 mil equipamentos portáteis, denominados laptops educacionais, para o atendimento de 300 escolas do Piloto do Projeto "Um Computador por Aluno (UCA)", na forma e condições estabelecidas no presente Edital e seus Anexos. Disponível em: <https:// contas.tcu.gov.br/juris/SvlHighLight;jsessionid=92BF2F113FA3C5E73803CAB4DF3AF A70?key $=$ ACORDAO-LEGADO-80332\&texto $=50524 \mathrm{f} 432533413133373431323030393$ 22a\&sort $=$ RELEVANCIA\&ordem $=$ DESC $\&$ bases $=$ ACORDAO-LEGADO;DECISAO LEGADO;RELACAO-LEGADO;ACORDAO-RELACAO-LEGADO;\&highlight=\&pos icaoDocumento=0>. Acesso em: 16 jul. 2013.

BRASIL. IBGE. Censo Demográfico, 2010. Disponível em: < http://www.ibge.gov.br/home/ presidencia/noticias/imprensa/ppts/00000008473104122012315727483985.pdf > Acesso em: 15 jun. 2013.

BRASIL. Apresentação do PROUCA do Ministério da Educação, 2010. Disponível em: <http:// www.uca.gov.br/institucional/downloads/UCA-apresentacao-ClaudioAndre.pdf $>$ Acesso em: 11 jan. 2013. 
CARVALHO, Marcus Vinicius Corrêa. Moderno, Modernidade e Modernização: polissemias e pregnâncias. In: GIL, Natália; ZICA, Matheus da Cruz; FARIA FILHO, Luciano Mendes (Org). Moderno, modernidade e modernização: a educação nos projetos do Brasil - séculos XIX e XX. Belo Horizonte: Mazza edições, 2012.

CAVALCANTI, Ana Mary. O Povo discute o uso da tecnologia na educação, 2012. Disponível em: <http://www.virtual.ufc.br/portal/reportagem-do-jornal-o-povo-discute-uso-datecnologia-na-educa\%C3\%A7\%C3\%A3o.aspx>. Acesso em: 20 jul. 2013.

FANTIN, Mônica; GIRARDELLO, Gilka. Diante do abismo digital: mídia-educação e mediações culturais. Revista Perspectiva. Florianópolis, v. 27, n. 1, p. 69-96, jan./jun. 2009. Disponível em: <http://www.perspectiva.ufsc.br/perspectiva_2009_01/Monica_Gilka. pdf $>$. Acesso em: 16 jul. 2013.

FARIA FILHO, Luciano Mendes de. Escolarização e cultura escolar no Brasil: reflexões em torno de alguns pressupostos e desafios. In: BENCOSTA; Marcos Levy Albino (Org.). Culturas escolares, saberes e práticas educativas: itinerários históricos. São Paulo: Cortez, 2007, p. 192-211.

GLADSTONE, Darren. Netbooks: tudo o que você deve saber a respeito desses PCs portáteis, 2009. Disponível em: <http://pcworld.uol.com.br/dicas/2009/03/04/netbookstudo-o-que-voce-precisa-saber-sobre-esses-pcs-portateis/>. Acesso em: 30 jun. 2013.

HOUAISS, Antônio. Dicionário Houaiss da Lingua Portuguesa. Rio de Janeiro: Ed. Objetiva, 2001.

IBIAPINA, I. M. L de M.; RIBEIRO, M. M. G.; FERREIRA, M. S. (Org.). Pesquisa em educação: múltiplos olhares. Brasília: Líder Livro Editora, 2007.

INTEL. Intel Classmate PC Um Computador por Aluno, 2009. Disponível em: <http:/ /www. teachertube.com/viewVideo.php?video_id=179213 >. Acesso em: 30 jul. 2013.

INTEL. Education Solutions, 2012. Apresentação Intel Classmate PC. Disponível em: < http:/ / www.intel.com/content/www/br/pt/education-solutions/classmatepc-convertible.html>. Acesso em: 20 jul. 2013.

JORNALDA CIÊNCIA. Cientista assume o comando da Intel nopaís, de 11 de março de 2011. Disponível em: <http:/ / www.jornaldaciencia.org.br/Detalhe.jsp?id=76694>. Acesso em: 20 jul. 2013.

LAWN, Martin. Uma pedagogia para o público: o lugar de objetos, observação, produção mecânica e armários-museus. Revista Linhas. Florianópolis, v. 14, n. 26, p. 222-243, jan./jun. 2013.

MENESES, Ulpiano B. Memória e cultura material: documentos pessoais no espaço público. Estudos Históricos. Rio de Janeiro, v. 11, n. 21, p. 89-104, 1998.

METASYS. Produtos Metasys, 2012. Disponível em: <http://www.metasys.com.br/index. php?option=com_content\&view=article\&id=220\&Itemid=29\&lang=pt $>$. Acesso em: 20 jul. 2013.

MILLER, Daniel. Trecos, troços e coisas: estudos antropológicos sobre a cultura material. Tradução de Renato Aguiar. Rio de Janeiro: Zahar, 2013.

PESEZ, Jean-Marie. História da cultura material. In: LE GOFF, J. $A$ história nova. $5^{\text {a }}$ ed. São Paulo: Martins Fontes, 2005, p. 177-214.

SANTA CATARINA. Números do Brasil, 2012. Disponível em: < http://www. todospelaeducacao.org.br/educacao-no-brasil/numeros-do-brasil/dados-por-estado/santacatarina/>. Acesso em: 20 jul. 2013.

SANTA CATARINA. Informativo do Aplicação, 2011. Florianópolis, Colégio Aplicação UFSC, ano 2, n. 4. Disponível em: <http://ca.ufsc.br/informativo/informativo.pdf>. Acesso em: 20 jul. 2013. 
SANTA CATARINA. Projeto Aulas Conectadas? Mudanças curriculares e aprendiragem colaborativa entre as escolas do projeto UCA em Santa Catarina nos anos de 2012 e 2013, de 2010. Financiado pelo CNPQ a partir do Edital CNPq/Capes/SEED-MEC nº 76/2010. Disponível em: <http://aulasconectadas-sc.blogspot.com.br/>. Acesso em: 20 jul. 2013.

SEVERINO, Antonio Joaquim. Metodologia do Trabalbo Científico. São Paulo: Cortez, 2007.

SOUZA, Rosa Fátima de. História da Cultura Material Escolar: um balanço inicial. In: BENCOSTA, Marcos Levy Albino (Org.). Culturas escolares, saberes e práticas educativas: itinerários históricos. São Paulo: Cortez, 2007, p. 163-189.

VIDAL, Diana Gonçalves. A invenção da modernidade educativa: circulação internacional de modelos pedagógicos, sujeitos e objetos no oitocentos. In: CURY, Cláudia Engler; MARIANO, Serioja Cordeiro (Orgs.). Múltiplas visões: cultura histórica no oitocentos. João Pessoa: Editora UFPB, 2009, p. 37- 54.

VIÑAO FRAGO, Antonio. El espacio y el tiempo escolares como objecto histórico. Contemporaneidade e Educação (Temas de História da Educação). Rio de Janeiro, Instituto de Estudos da Cultura Escolar, ano 5, n. 7, p. 93-110, $1^{\circ}$ semestre, 2000.

\section{NOTAS}

${ }^{1}$ Ver Martin Lawn (2013, p. 230).

${ }^{2}$ Ambiente Colaborativo de Aprendizagem do Ministério da Educação.

${ }^{3}$ Programa Nacional de Tecnologia Educacional (ProInfo), do Ministério da Educação. É um programa educacional com o objetivo de promover o uso pedagógico da informática na rede pública de educação básica. O programa leva às escolas computadores, recursos digitais e conteúdos educacionais. Em contrapartida, estados, Distrito Federal e municípios devem garantir a estrutura adequada para receber os laboratórios e capacitar os educadores para uso das máquinas e tecnologias. Disponível em: <http://portal.mec.gov.br/index. php?Itemid=462> Acesso em: 18 jul. 2013.

${ }^{4}$ Os laptops educacionais destinados às escolas através desse programa ficaram conhecidos como UCA, nomenclatura que usaremos no transcorrer deste artigo.

${ }^{5}$ Idealizador do Projeto One Laptop per Child - OLPC - (Um Computador por Criança), também Presidente da Fundação OLPC, instituição sem fins lucrativos, mantida pelas Empresas: Google, News Corp, AMD, ReadHat, Brightstar, Nortel e Intel. É necessário indicar que a fundação foi criada após a apresentação do Projeto OLPC em 2005 no Fórum de Davos. Informações obtidas no estudo de: BORGES; SANTOS, 2008. Outros países também adotaram o Projeto do pesquisador norte americano, como a Argentina que está desenvolvendo o Programa Nacional "Una Computadora para cada Alumno", parte integrante do Programa Conectar Igualdad.

${ }^{6}$ Faz-se relevante destacar que o dimensionamento educacional desse Programa PROUCA tem como proposta de avaliação os seguintes itens: 1. escola e laptops; 2. projeto pedagógico; 3. parcerias; 4. gestão pedagógica; 5. formação inicial; 6. práticas pedagógicas já existentes na escola; 7. indicadores da escola e do município; 8. perfil cognitivo e social; 9. equipe responsável pelo Projeto UCA; 10. perfil sociodemográfico dos alunos; 11. expectativas da comunidade escolar; 12. expectativas dos pais dos alunos; 13. inclusão digital no município. Todos esses itens estão expressos no documento de apresentação do PROUCA do Ministério da Educação (2010). Disponível em:< http://www.uca.gov.br/institucional/downloads/ UCA-apresentacao-ClaudioAndre.pdf > Acesso em: 11 jan. 2013. 
${ }^{7} \mathrm{O}$ projeto, contemplado com o auxílio pesquisa, envolveu cinco diferentes instituições: Universidade do Estado de Santa Catarina (UDESC), Colégio de Aplicação da Universidade Federal de Santa Catarina (CA - UFSC), Universidade da Região de Joinville (UNIVILLE) e o Núcleo de Tecnologia da Prefeitura Municipal de Florianópolis, além das redes estaduais e municipais de ensino, por meio dos seus núcleos de tecnologia e das escolas envolvidas.

${ }^{8}$ Informações sobre o projeto disponíveis em: <http://aulasconectadas-sc.blogspot.com.br/>.

${ }^{9}$ No contexto atual, a primeira e a segunda pergunta se situam geralmente em abordagens do tipo: "A escola não pode se manter distante do mundo (virtual) lá fora, concordam diretores ou gestores dos colégios visitados pelo O POVO. O argumento é o primeiro da lista de porquês que respondem à necessidade de conectar o aprendizado a novas tecnologias." Disponível em:<http://www.virtual.ufc.br/portal/reportagem-do-jornal-o-povodiscute-uso-da-tecnologia-na-educa\%C3\%A7\%C3\%A3o.aspx>Acesso em: 11 jan. 2013. $\mathrm{Na}$ contramão de tais enunciados, são importantes as perspectivas de Fantin e Girardello (2009, p. 71-72) para constituírem um estudo sobre inclusão digital, quando afirmam: “[...] um primeiro pressuposto deste trabalho é a necessidade de pensarmos o acesso à cultura digital de forma dialética, deixando de lado qualquer iluminismo ingênuo ou perspectivas assistencialistas de distribuição de equipamentos. Buscaremos nos afastar também da lógica da integração globalizada e da dicotomia entre atraso e modernidade que impele populações inteiras à corrida pelos gadgets eletrônicos de cada temporada. Examinar a inclusão digital em países ditos periféricos exige atenção às manifestações culturais que correm por fora do ciberespaço, entendendo essa ausência não necessariamente como atraso, pobreza simbólica ou incompetência, mas sim como diferença valiosa e eloquente, possível lugar de constituição crítica. Exige ainda atenção às políticas públicas de formação de educadores, assim como a programas especiais de educação e cultura".

${ }^{10}$ Entende-se por tecnologia digital todo aparato que funciona em um circuito eletrônico binário, segundo definição do Houaiss (2001) tecnologia é: “Todo o processo tecnológico de telecomunicação e computação que permite transmitir, armazenar, disseminar, receber e otimizar a circulação de informações através de redes globalizantes" e digital: "Relativo a dedos ou que tem analogia com eles, relativo a dígito (algarismo); Exemplo: computadores, notebooks, netbooks, telefonia móvel, máquinas de imagens médicas, projetores, etc".

${ }^{11}$ Computadores pessoais lançados com essa nomenclatura pela empresa Intel, se apresentam como ultra portáteis e com configurações iniciais de uma máquina básica. Disponível em: $<$ http://pcworld.uol.com.br/dicas/2009/03/04/netbooks-tudo-o-que-voce-precisa-sabersobre-esses-pcs-portateis/>. Acesso em: 30 jul. 2013.

${ }^{12} \mathrm{~A}$ empresa Intel quando começou a desenvolver os equipamentos para o PROUCA, e para o consumo de outros programas ou empresas de educação, lançou um vídeo no qual argumenta que esse equipamento fora pensado para a infância. O design e o modelo do UCA estariam na contramão do laptop máquina de trabalho, uma vez que ele aciona constantemente a relação mobilidade, que deve haver para a infância, como debruçar sobre as mesas dos colegas, carregar o equipamento de um lado para o outro, dando a isso uma condição de estudo para o infante e jovem estudante. Esse vídeo remete a algumas reflexões existentes entre os objetos de estudos que não diferiam do mundo adulto, lápis, caneta e outros iguais entre o mundo adulto e o mundo escolar. Para outras informações acessar: <http://www.teachertube.com/ viewVideo.php?video_id=179213>. Acesso em: 30 jul. 2013.

${ }^{13} \mathrm{Um}$ dos parceiros do PROUCA, a OLPC desenvolveu o seu "laptop educacional - OX" que ficou conhecido como o computador que deveria ter preço de custo de US $\$ 100$. 
${ }^{14}$ Ao refletir sobre "alfabetização técnica" Lawn (2013, p. 230), se refere à análise de Stevens quando este argumenta a necessidade do aparecimento de uma nova habilidade a ser aprendida, "a representação gráfica espacial”, cuja materialidade foi imprescindível para tal.

${ }^{15}$ Ver adiante a relação do aluno com a técnica diante desse equipamento quando o recebem no Colégio de Aplicação - UFSC.

${ }^{16}$ ABADE, Luciana. MEC: Programas de inclusão digital estão entre os maiores do mundo. Jornal do Brasil, 03 de abril de 2010. Disponível em: < http://www.jb.com.br/ pais/noticias/2010/04/03/mec-programas-de-inclusao-digital-estao-entre-os-maiores-domundo/> Acesso em: 12 jul. 2013.

${ }^{17}$ Dados apresentados no site do Programa UCA. Ver: <http://www.uca.gov.br/ institucional/criteriosEscolha.jsp>. Acesso em: 20 nov. 2012.

${ }^{18}$ Por exemplo, no estado de Santa Catarina somente 19 escolas foram contempladas, tendo 5.670 alunos atendidos, segundo dados apresentados pelo PROUCA. Ver: <http://www. uca.gov.br/institucional/escolasBeneficiadas.jsp.>. Acesso em: 20 nov. 2012. Contudo, o universo escolar de Santa Catarina é de aproximadamente 1.367.703 alunos (em idade escolar em 2010), segundo dados do Programa Todos pela Educação. Ver: <http://www. todospelaeducacao.org.br/educacao-no-brasil/numeros-do-brasil/dados-por-estado/santacatarina/>. Acesso em: 20 jul. 2013.

${ }^{19}$ Cabe esclarecer que, apesar de Carvalho (2012) não tratar da inclusão digital, o sentido de marginalização que o autor argumenta em relação à modernização nas escolas colabora para o entendimento do contexto de uma política de inclusão digital que se dá pela inserção desigual do computador e das condições de sua realização nos moldes propostos.

${ }^{20}$ Como parte do argumento até agora tecido, a perspectiva do contexto de uma política de inclusão digital que se dá pela inserção desigual do computador e das condições de sua realização nos moldes propostos. Em entrevista, o Presidente da Intel no Brasil fala da aproximação da empresa com esse tipo de projeto e da necessidade de ampliar a interação com as empresas locais do processo de modernização na escola pelas reformas e políticas englobando a materialidade contida nesse espaço e também a resposta de ensino e aprendizagem do seu domínio. Ver: <http://www.jornaldaciencia.org.br/Detalhe. jsp?id=76694>. Acesso em: 11 jan. 2013.

${ }^{21}$ Dados obtidos no site: <http://www.uca.gov.br/institucional/escolasBeneficiadas.jsp>. Acesso em: 10 jul. 2012.

${ }^{22}$ Informações sobre a implantação do PROUCA no Colégio Aplicação UFSC. Ver: < http:/ / ca.ufsc.br/informativo/informativo.pdf>. Acesso em: 20 jul. 2013.

${ }^{23}$ Diante dos problemas apresentados com o sistema operacional Metasys houve o recolhimento de todos os UCA's no Colégio de Aplicação para formatá-los e instalar o UBUNTU - sistema reconfigurado do Linux para adequar-se ao hardware.

${ }^{24}$ Empresa de Comércio de Componentes Eletrônicos. Ver: <http://www.cce.com.br/ Institucional/QuemSomos>. Acesso em: 09 jan. 2013.

${ }^{25}$ Quando se evidencia as dificuldades das questões tecnológicas na escola que se articulam entre as práticas sociais e culturais dos alunos.

${ }^{26}$ PortableDocumentFormat ou Documento de formato portátil. É um formato arquivo para leitura, que mantém a aparência de textos, imagens e gráficos, ou seja, conserva o documento original. Esse formato foi criado pela AdobeAcrobat Reader e é fornecido gratuitamente. 
${ }^{27} \mathrm{O}$ referido Pregão é realizado em 2008, mas parte da legislação que decreta a criação do PROUCA, as diretrizes dessa política e os modelos do equipamento que deveriam chegar até a escola, só acontecem em 2010.

${ }^{28}$ Refere-se à capacidade em gigabytes da memória, tendo por definição: múltiplo do byte, que vale 1.024 megabytes (símb.: GB) [Frequentemente, arredonda-se o valor do gigabyte para mil megabytes]. Houaiss, 2001. Disponível em: <http://houaiss.uol.com.br/>. Acesso em: 19 fev. 2015.

${ }^{29}$ Expressão em inglês RandomAcessMemory (memória de acesso aleatório). Houaiss (2001). Disponível em: <http://houaiss.uol.com.br/>. Acesso em: 19 fev. 2015.

${ }^{30}$ Referimo-nos às crianças do $4^{\circ}$ e $5^{\circ}$ anos iniciais do Ensino Fundamental porque esse grupo fez parte do Projeto Aulas Conectadas. Contudo, é possível inferir que tais situações também faziam parte da prática social e cultural dos três primeiros anos iniciais do Ensino Fundamental.

${ }^{31}$ Ver: Lawn (2013).

Recebido: 30/09/2014

Aprovado: 13/03/2015

Contato:

Universidade do Estado de Santa Catarina - UDESC Centro de Ciências Humanas e da Educação - FAED Avenida Madre Benvenuta, 2007 - Itacorubi

Prédio da FAED - Sala 34

Florianópolis $|\mathrm{SC}|$ Brasil

CEP 88.035-001 